\title{
Exploring Vegetative Propagation Techniques for the Threatened Pteroceltis tatarinowii Maxim Using Stem Cuttings
}

\author{
Zhaohui Li', Yan Ma', Wanyuan Yin, Dekui Zang ${ }^{2}$, and Xianfeng Guo ${ }^{2}$ \\ College of Forestry, Shandong Agricultural University (SDAU), Key \\ Laboratory of State Forestry Administration for Silviculture of the lower \\ Yellow River, Taian, Shandong 271018, China
}

Additional index words. rooting, adventitious roots, IBA

\begin{abstract}
Pteroceltis tatarinowii Maxim, the only species of the genus Pteroceltis (family Ulmaceae), is an endemic rare tree species in China. This study was performed to explore vegetative propagation techniques for $P$. tatarinowii using stem cuttings. First, the effects of exogenous indole-3-butyric acid (IBA) and cutting positions on rooting performance were investigated to screen the appropriate exogenous auxin treatment and to determine the proper cuttings type. The results showed that the control cuttings pretreated with no exogenous IBA, irrespective of whether the stem cuttings were terminal, middle, or basal, rooted in a manner significantly inferior to that of cuttings pretreated with IBA. Their rooting percentage was less than $50 \%$. Among the IBA-treated cuttings, the middle cuttings pretreated with $1000 \mathrm{mg} \cdot \mathrm{L}^{-1}$ IBA rooted best, with the shortest number of days until rooting emergence (20 days), the highest rooting percentage $(84.0 \%)$, the lowest mortality rate $(4.0 \%)$, the greatest root number (average of 6.7 per cutting), and the longest roots per cutting $(44.4 \mathrm{~cm}$ per cutting). Terminal cuttings pretreated with $1000 \mathrm{mg} \cdot \mathrm{L}^{-1} \mathrm{IBA}$ acquired satisfactory rooting traits and had the same shortest rooting duration (20 days) and the following parameters: rooting, $70.7 \%$; mortality, $10.7 \%$; average roots per cutting, 5.2 ; and longest root, $29.1 \mathrm{~cm}$. To further determine the optimum cutting propagation time for this plant, a second experiment was performed and the cuttings were collected beginning in early June, when the growth of the current season was feasible for harvesting cuttings. Stem cuttings collected in late June and middle July had significantly higher rooting percentages $(\geq 80 \%)$ compared with those collected in early June $(66.7 \%)$. The other three rooting parameters were not significantly affected by the collection date. However, according to the overall rooting traits, the cuttings collected in both late June and middle July remarkably outperformed those collected in early June regarding the number of roots and the total root length per cutting. The initial nutrient reserves in the cuttings were also determined. A significant difference in the soluble carbohydrate level was found among collection times, but the nitrogen level in the cuttings was similar. The study revealed that stem cutting propagation of $P$. tatarinowii was achievable, and it was best achieved with cuttings collected from the terminal and middle positions of the branches of the current season from late June to middle July and treated with $1000 \mathrm{mg} \cdot \mathrm{L}^{-1}$ IBA using the quick dip method.
\end{abstract}

Pteroceltis tatarinowii Maxim, the only species of the genus Pteroceltis (family Ulmaceae) and one of the tertiary relict plants, is unique to China and has been found in 19 provinces, such as Gansu, Guizhou, Anhui, Jiangsu, Shandong, Hubei, and Hunan (Li et al., 2013). Since ancient times, its bark

Received for publication 5 Nov. 2018. Accepted for publication 13 Jan. 2019.

This study was funded by the project of "collection, conservation, and evaluation of forest trees" (2010-6) sponsored by the Department of Science and Technology of Shandong Province, Shandong Provincial Agricultural Elite Varieties Project (2016LZGC038), and Forestry Science \& Technology Innovation Project of Shandong Province (LYCX01-2018-03), China.

${ }^{1}$ These authors contributed equally to this work. ${ }^{2}$ Corresponding authors. E-mail: zangdk@sdau. edu.cn or guoxf@sdau.edu.cn. has been widely used as the main raw material for manufacturing traditional Chinese Xuan paper because of its fiber richness (Fang et al., 2004). More recently, it has been recognized for its ornamental value and versatile habitat; therefore, it is being increasingly used in urban landscaping. However, it was listed as an endemic rare tree species in China (Fu, 1991), and it remains rare (Fang et al., 2004; Li et al., 2013).

To meet the expanding demand, many studies of propagation techniques have been performed during the past 20 years. Previous studies mainly focused on seedling culture techniques (An et al., 2011; Sheng, 2006; Yang and Fang, 1996) or seedling growth and physiology (Fu et al., 2001; Liu et al., 2011; Wei et al., 2007). Obviously, propagation by seeds leads to genetic variability and is not suitable for sustaining populations of the species or reproducing improved cultivars or strains. Therefore, vegetative propagation techniques, especially cutting propagation techniques, which have been widely used in the mass production of many other woody plants (Howard, 1996; Phillip et al., 2014; Tworkoski and Takeda, 2007), should be considered. However, so far, few reports of cutting propagation of $P$. tatarinowii have been published.

The present study was performed to explore stem cutting techniques for $P$. tatarinowii. The specific objectives were, first, to screen the appropriate exogenous auxin treatment and determine the cutting type by testing the effects of gradient concentrations of indole-3-butyric acid (IBA) and cutting positions on rooting performance and, second, to investigate the effects of the collection times of cuttings on rooting performance and to interpret changes in the initial nutrient reserves of cuttings that are related to rooting responses.

\section{Materials and Methods}

Two experiments were performed during two consecutive years. The first experiment was conducted on 14 July 2012; the second one was conducted during 2013.

Expt. 1: Effects of IBA concentrations and cutting positions on the classification of rooting cuttings according to their position on branches. Healthy and uniform current season branches outside of the canopy $(50-70 \mathrm{~cm}$ in length, $0.2 \mathrm{~mm}$ in thickness) (Fig. 1) were taken from 4-year-old $P$. tatarinowii plants growing in Forestry Experimental Nursery (lat. $36^{\circ} \mathrm{N}$, long. $117^{\circ} \mathrm{E}$ ), Shandong Agricultural University, Tai'an, Shandong Province, P.R. China. The extreme basal and terminal parts were removed. Then, the remainder of the branches was sectioned into cuttings $9-11 \mathrm{~cm}$ long with three to four nodes. These were separated into three different groups, terminal, middle, and basal (Fig. 1), according to their position on the branch and lignification status.

To reduce water loss, the bottom leaves of all cuttings were removed, with one leaf retained. All cuttings were surface-sterilized by immersion in $0.3 \%(\mathrm{w} / \mathrm{v}) \mathrm{KMnO}_{4}$ for $5 \mathrm{~min}$ and subsequently washed with tap water. Then, they were naturally dried for $10 \mathrm{~min}$ before IBA treatment.

IBA treatment. Before sticking the cuttings, each type of cutting (terminal, middle, or basal) was treated with different concentrations of IBA solution $(0,500,1000,1500$, and $\left.2000 \mathrm{mg} \cdot \mathrm{L}^{-1}\right)$. The basal $1 \mathrm{~cm}$ of the cuttings was immersed in the IBA solution for $\approx 15 \mathrm{~s}$. Then, these pretreated cuttings were vertically stuck in the premade holes in clean sand beds. There were three replications with 25 cuttings per treatment. A randomized complete block design was used for this experiment.

IBA solutions were prepared by dissolving the appropriate amount of IBA in $50 \mathrm{~mL}$ of $70 \%$ alcohol and adding distilled water to a total volume of $100 \mathrm{~mL}$. The prepared IBA solutions were stored at $4{ }^{\circ} \mathrm{C}$ in opaque bottles and used within $2 \mathrm{~d}$.

Management of environmental conditions. The experiment was conducted in a plastic 
propagation tunnel with a shade net. The air temperature in the plastic tunnel was maintained at 20 to $30{ }^{\circ} \mathrm{C}$, with $70 \%$ to $85 \%$ relative humidity supplied by an intermittent mist system. To control fungal disease, $50 \%$ carbendazol (diluted 800 times) and $0.3 \%(\mathrm{w} / \mathrm{v})$ $\mathrm{KMnO}_{4}$ were sprayed alternately every $5 \mathrm{~d}$ during the rooting period.

Rooting data collection and statistical analysis. After $60 \mathrm{~d}$, the cuttings from each treatment were carefully dug out from the sand bed. Then, rooting parameters were determined and recorded. The parameters included rooting percentage, mortality percentage, number of primary roots per cutting, and total root length per cutting. The obtained data were subjected to an analysis of variance, and the means were compared using Tukey's honestly significant difference test at a level of 5\% using SPSS (SPSS 19.0; SPSS Inc. Chicago, IL). Rooting percentage data were arcsine-transformed before the analysis to obtain normality.

Expt. 2: Effects of collection time and initial nutrient reserves of cuttings on rooting. Cuttings were collected on 4 June, 24 June, and 14 July 2013. According to the results of Expt. 1, only terminal cuttings and middle cuttings were used in this experiment. These cuttings were pretreated with $1000 \mathrm{mg} \cdot \mathrm{L}^{-1} \mathrm{IBA}$ (the optimum concentration according to Expt. 1) using the quick dip method.

For each collection time, there were three replications of 25 cuttings. A randomized complete block design was used during this experiment. Environmental management of the propagation tunnel was similar to that of Expt. 1. After $60 \mathrm{~d}$, the rooting data were collected and the statistical analysis was performed in the same manner as during Expt. 1.

Determination of the initial nutrient reserves of cuttings. At each collection date, 25 additional stem cuttings were randomly collected for the determination of nutrient reserves. The basal portion $(\approx 1 \mathrm{~cm}$ long) of the cuttings were collected to be dried (in an oven at $105^{\circ} \mathrm{C}$ for $20 \mathrm{~min}$ and then at $80^{\circ} \mathrm{C}$ for constant weight) and grounded. Then, a $0.1-\mathrm{g}$ dry sample was weighed for further measurements. Soluble carbohydrates were determined using the anthrone colorimetric technique, as described by Zhou (2000). The nitrogen content was determined using the Kjeldahl technique, as described by Cavins (1980) and Zhou (2000). All analyses were repeated three times.

\section{Results}

Morphological changes during the adventitious rooting process. During Expt. 1, cuttings in the propagation shelter (Fig. 2A) were monitored every $5 \mathrm{~d}$ during the adventitious rooting process. The earliest morphological change occurred among the terminal and middle cuttings pretreated with $1000 \mathrm{mg} \cdot \mathrm{L}^{-1}$ of IBA, which corresponded to their best rooting performance (data seen in Fig. 3). The visible external morphological change comprised basal swelling and callus formation around the cut surface of cuttings on day 5 (Fig. 2B), callus mass enlargement and enhancement on day 10 (Fig. 2C), emergence of

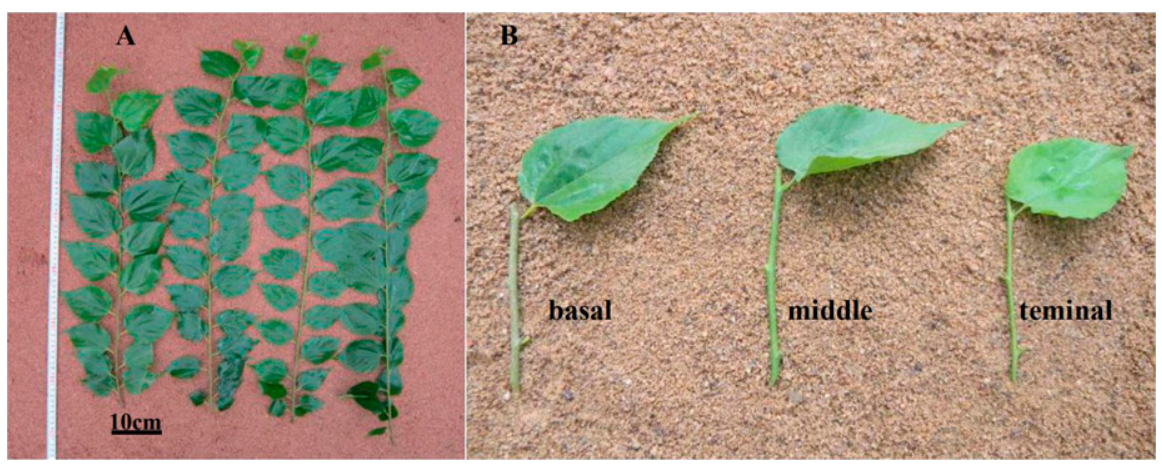

Fig. 1. Growth of the branches of P. tatarinowii (A) and cuttings from different positions of the branches (B) during the current season.
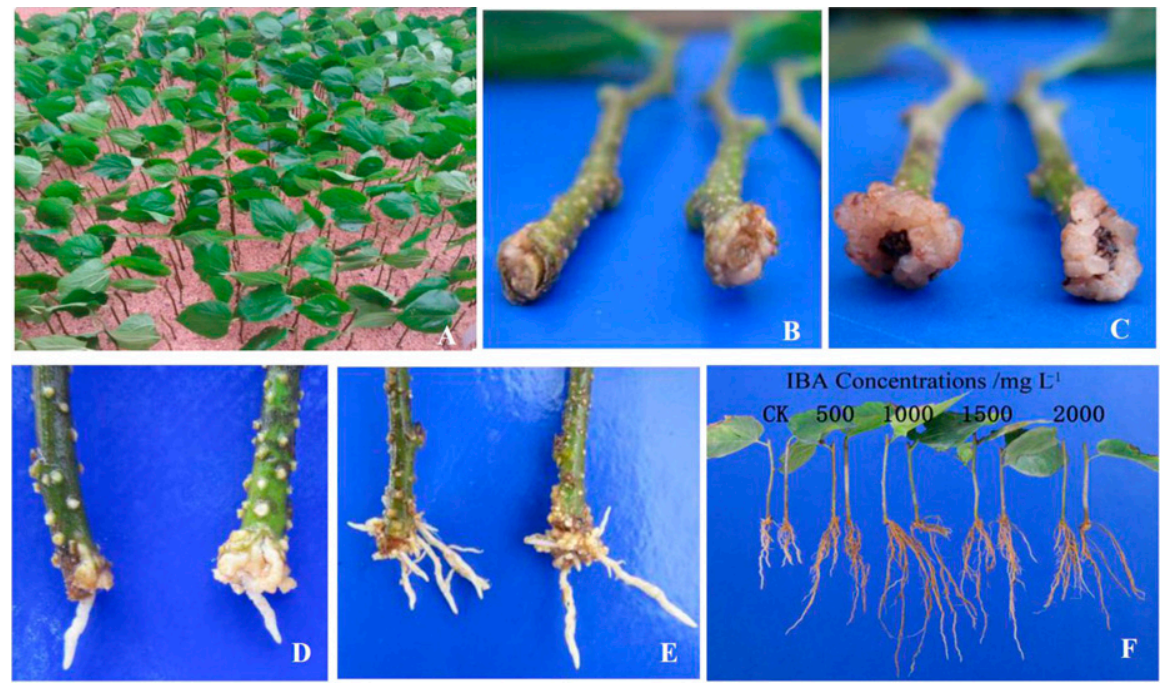

Fig. 2. Morphological changes in $P$. tatarinowii cuttings and rooting variation when pretreated with different concentrations of IBA: (A) cuttings in the propagation shelters; (B) callus formation on day 5; (C) callus plump enlarged on day 10; (D) adventitious root emerged on day 20; (E) multiple adventitious roots formed on day 25 ; and $(\mathbf{F})$ rooting response of middle cuttings varied with the IBA concentration on day 60 .

adventitious roots through the callus on day 20 (Fig. 2D), and formation of multiple adventitious roots and elongation of adventitious roots during the following days (Fig. 2E).

In the control cuttings, the callus also emerged on day 5 , but it grew slowly. Fewer than $50 \%$ of cuttings formed tiny adventitious roots by day 60 . Moreover, the leaves of the control cuttings always turned yellow and ultimately fell off.

Regarding the cuttings pretreated with other concentration of IBA solution, the morphological change was the same as that of those pretreated with $1000 \mathrm{mg} \cdot \mathrm{L}^{-1}$ IBA, except there was a time delay of 5 to $10 \mathrm{~d}$.

Effects of IBA treatment and cutting positions on rooting. After $60 \mathrm{~d}$, three types of growth responses were detected in all cuttings: rooted, callused but with no roots, and dead due to decay. Each parameter for assessing the rooting performance was significantly affected by the IBA concentration or cutting position (Fig. 3). The rooting performance varied in the middle cuttings pretreated with different concentrations of IBA on day 60 (Fig. 2F). Regardless of the cutting position, the cuttings not pretreated with IBA rooted in a significantly inferior manner compared to the IBA-treated cuttings, with the lowest rooting percentage (less than $50 \%$ ), the highest mortality $(\approx 25 \%)$, the smallest root number per cutting (less than 4), and the shortest total root length (smaller than $25 \mathrm{~cm}$ ).

Among the IBA-pretreated cuttings, the middle cuttings pretreated with $1000 \mathrm{mg} \cdot \mathrm{L}^{-1}$ IBA had the best rooting performance, with the greatest rooting percentage $(84.0 \%)$, the least mortality $(4.0 \%)$, the highest mean root number (6.67), and maximum total root length $(44.43 \mathrm{~cm})$. The next overall superior rooting performance occurred in middle cuttings pretreated with $1500 \mathrm{mg} \cdot \mathrm{L}^{-1} \mathrm{IBA}$ and in terminal cuttings pretreated with 1000 and $1500 \mathrm{mg} \cdot \mathrm{L}^{-1}$ IBA. These three treatment combinations produced more than $70 \%$ rooting, with no statistically significant difference among them. Moreover, the mortality of these cuttings was relatively lower, ranging from $6.67 \%$ to $10.67 \%$. The root number per cutting ranged from 5.2 to 6.67 , with a relatively high total root length ranging from $29.05 \mathrm{~cm}$ to $35.43 \mathrm{~cm}$.

As described previously, the terminal or middle cuttings pretreated with $1000 \mathrm{mg} \cdot \mathrm{L}^{-1}$ 
A

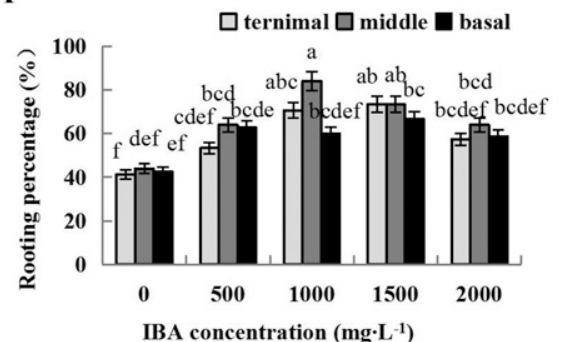

C

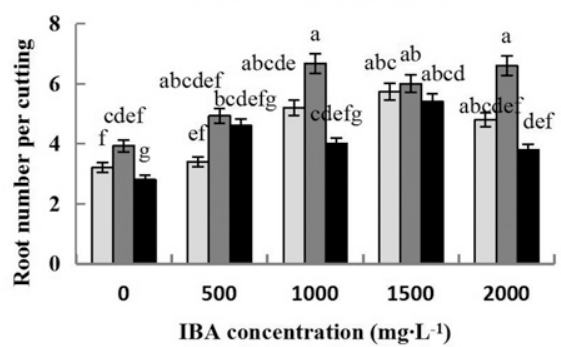

B

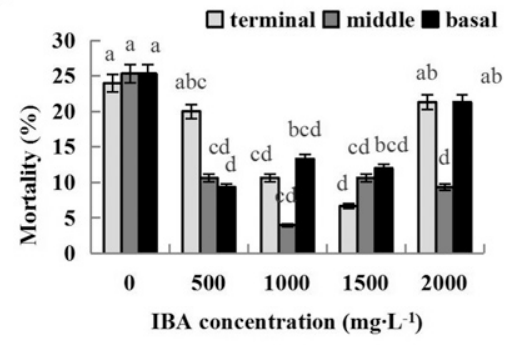

D

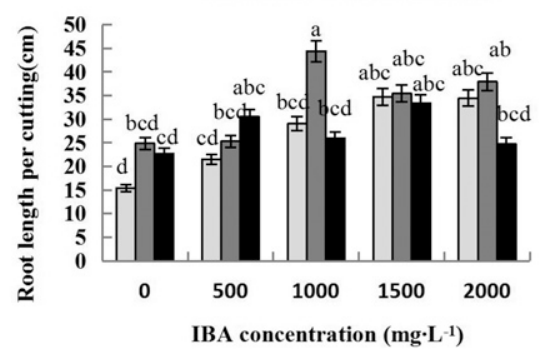

Fig. 3. Effects of IBA concentrations and cutting positions on: (A) rooting percentage; (B) percent mortality; (C) mean root number per cutting; and (D) total root length. Notes: The same letters above the different columns indicate no significant difference at $P \leq 0.05$. Error bars represent standard error.

IBA formed adventitious roots on day 20 , which was 5-10 d earlier than that observed in other cuttings. Considering these rooting responses together, $1000 \mathrm{mg} \cdot \mathrm{L}^{-1}$ IBA was considered the optimum concentration. Cuttings from the terminal and middle sections pretreated with $1000 \mathrm{mg} \cdot \mathrm{L}^{-1}$ IBA were therefore used for Expt. 2.

Effects of collection time and nutrient level on rooting. When using cuttings pretreated with $1000 \mathrm{mg} \cdot \mathrm{L}^{-1} \mathrm{IBA}$, rooting performance varied with the collection time (Table 1). Among the four parameters investigated, the rooting percentage significantly differed among the three collection dates. The higher rooting percentage occurred in the cuttings collected on 24 June or 14 July, with rooting percentages of $82.67 \%$ and $80 \%$, respectively, which were significantly higher than that $(66.67 \%)$ observed in the cuttings collected on 4 June. Moreover, the cuttings from 24 June and 14 July had superior rooting performance in terms of the other three rooting parameters, both with no more than $8 \%$ mortality, $\approx 6$ roots per cutting, and total root length more than 45 $\mathrm{cm}$. In addition, it was observed that the adventitious roots from these cuttings occurred $10-15 \mathrm{~d}$ earlier than those from cuttings collected on 4 June, which required $30-35 \mathrm{~d}$.

Concentrations of soluble carbohydrates and nitrogen in cuttings also varied with the cuttings collection date (Table 1). Furthermore, it was found that soluble carbohydrates significantly increased with the progress of the collection date $(1.28 \%, 1.80 \%$, and $2.06 \%$ on 4 June, 24 June, and 14 July, respectively). This trend was consistent with improved rooting traits as collection time progressed. In comparison, nitrogen content in the cuttings collected from different periods exhibited no significant differences $(0.075 \%, 0.072 \%$, and $0.070 \%$ on 4 June, 24 June, and 14 July, respectively).

\section{Discussion}

$P$. tatarinowii is listed as an endangered rare plant in China. However, efficient propagation techniques will greatly facilitate the domestication, selection, and improvement of the species. The results of this study clearly suggested that stem cutting propagation was possible for mass propagation of $P$. tatarinowii, but the rooting capacity was limited (less than $50 \%$ rooting percentage) if cuttings were not pretreated with exogenous IBA. IBA has been widely used to promote adventitious root formation in plant cuttings (Guo et al., 2009; Phillip et al., 2014; Tworkoski and Takeda, 2007; Valerio et al., 2010). However, the dosage of applied IBA differed from species to species. The current results indicated that the enhancing effects on rooting performance of $P$. tatarinowii stem cuttings were weak when the IBA concentration was too low (such as $500 \mathrm{mg} \cdot \mathrm{L}^{-1}$ ) or too high (up to $2000 \mathrm{mg} \cdot \mathrm{L}^{-1}$ ). Similar effects on rooting caused by too low or too high exogenous auxin levels also occurred in other plants, including Dalbergia sissoo (Singh et al., 2012) and Amygdalus persica (Tworkoski and Takeda, 2007). For P. tatarinowii, we found that $1000 \mathrm{mg} \cdot \mathrm{L}^{-1}$ and 1500 $\mathrm{mg} \cdot \mathrm{L}^{-1}$ IBA were moderate concentrations because they demonstrated strong enhancing effects on the increasing rooting percentage, root number per cutting, and total root length. Moreover, we noticed that $1000 \mathrm{mg} \cdot \mathrm{L}^{-1} \mathrm{IBA}$ promoted early rooting by $5-10 \mathrm{~d}$. This additive advancing effect of IBA on shortening the adventitious rooting period coincided with the results of previous studies (Aminah et al., 1995; He et al., 2002). In general, according to the comprehensive results of the study, $1000 \mathrm{mg} \cdot \mathrm{L}^{-1}$ was recognized as the optimal and economic concentration for
P. tatarinowii stem cutting propagation and resulted in superior rooting performance.

The effect of the cutting position on the branch was also tested in the present study because this factor was shown to affect the rooting performance of many woody plants (Husen and Pal, 2007; Zalesny et al., 2003; Amri et al., 2010). The results suggested that all basal cuttings, irrespective of IBA pretreatment, had less than $70 \%$ rooting, which was significantly lower than that of terminal cuttings and middle cuttings (Fig. 3). Other tested rooting parameters of bottom cuttings were significantly or remarkably lower. These results corresponded with those of some other reports, such as one that involved Quercus rubra cutting propagation research (Ding and Huang, 2012), but they were not consistent with other study results, such as those for Jatropha curcas (Severino et al., 2011) and Dalbergia sissoo (Singh et al., 2012). The conflicting results might be attributed to tree variation. In the present study, the cutting position was tested in middle July, when the lignifying status of the basal cuttings might be somewhat deeper, which possibly led to the relatively poor rooting response of these cuttings.

Temporal variations in rooting efficiency are very common in woody plants such as Corylus avellana (Hazel) (Valerio et al., 2010), Boswellia papyrifera (Haile et al., 2011), and Ceanothus americanus (Dahurian buckthorn) (Julia and Jessica, 2013) The optimal time for rooting must be established individually for each species according to their growth characteristics (Howard, 1996; Klein et al., 2000). P. tatarinowii is a late sprouting species that usually bursts in late April and early May in Tai'an, Shandong province in China. After $\approx 1$ month of growth, the annual branches can achieve new growth of $50-70 \mathrm{~cm}$ in length with $\approx 20$ nodes from which 3 to 4 qualified cuttings can be obtained. Hence, three collection dates for cuttings, starting from early June, were designated, with an interval of $20 \mathrm{~d}$. The results demonstrated that cuttings harvested from late June and middle July produced significantly superior rooting performance compared to those from early June. Our study clearly revealed that stem cutting propagation of $P$. tatarinowii was achievable, and it was best achieved with cuttings from the terminal and middle positions of the branches of the current year collected during late June to middle July and treated with $1000 \mathrm{mg} \cdot \mathrm{L}^{-1}$ IBA using the quick dip method.

Additionally, we determined that the initial soluble carbohydrate level in cuttings significantly varied with the collection time, and that the $\mathrm{C} / \mathrm{N}$ ratio of IBA-treated cuttings was significantly different than that of cuttings not treated with IBA. The higher ratio of $\mathrm{C} / \mathrm{N}$ of the cuttings was favorable for the roots, and the theory of $\mathrm{C} / \mathrm{N}$ ratio was appropriate for $P$. tatarinowii softwood cutting. This implied that high soluble carbohydrate levels are conducive for adventitious rooting of $P$. tatarinowii cuttings, which was consistent with the results of previous studies 
Table 1. Rooting performance and initial nutrient level of Pteroceltis tatarinowii cuttings on different collection dates.

\begin{tabular}{|c|c|c|c|c|c|c|}
\hline \multirow[b]{2}{*}{ Collection date } & \multicolumn{4}{|c|}{ Rooting performance } & \multicolumn{2}{|c|}{ Initial nutrient level of cuttings (\% DW) } \\
\hline & Rooting percentage (\%) & Morality (\%) & Root number (roots) & Total root length $(\mathrm{cm})$ & Soluble carbohydrates & Total N \\
\hline 24 June & $82.67 \pm 2.65 \mathrm{a}$ & $8 \pm 6.98$ & $6.93 \pm 0.44$ & $46.51 \pm 1.95$ & $1.80 \pm 0.13 \mathrm{a}$ & $0.072 \pm 0.01$ \\
\hline
\end{tabular}

${ }^{\mathrm{z}}$ The \pm values in each column indicate the standard errors. The same letters next to the \pm values within a column indicate no significant difference at $P \leq 0.05$.

(Denaxa et al., 2012; Guo et al., 2004). Therefore, we suggested that increasing the carbohydrate level in the cuttings of stock plants should be achieved during $P$. tatarinowii nursery management so that the cuttings themselves accumulate sufficient nutrients.

\section{Literature Cited}

Aminah, H., J. McP. Dick, R.R.B. Leakey, J. Grace, and R.I. Smith. 1995. Effect of indole butyric acid (IBA) on stem cuttings of Shorea leprosula. For. Ecol. Mgt. 72:199-206.

Amri, E., H.V.M. Lyaruu, A.S. Nyomora, and Z.L. Kanyeka. 2010. Vegetative propagation of African Blackwood (Dalbergia melanoxylon Guill. \& Perr.): Effects of age of donor plant, IBA treatment and cutting position on rooting ability of stem cuttings. New For. 39:183-194.

An, G.C., C.J. Zhang, L. Wang, and F. An. 2011. Seeding technique of Pteroceltis tatarinowii using protective facility. Practical For. Technol. 1:22-24 (in Chinese)

Cavins, J.F. 1980. Nitrogen analysis of whole seeds. J. Amer. Oil Chem. Soc. 57:655-656.

Denaxa, N.K., S.N. Vemmos, and P.A. Roussos. 2012. The role of endogenous carbohydrates and seasonal variation in rooting ability of cuttings of an easy and a hard to root olive cultivars (Olea europaea L.). Scientia Hort. 143:9-28.

Ding, T. and C.L. Huang. 2012. Research on the cutting propagation of Quercus rubra. J. of Anhui Agr. Univ. 39:507-513 (in Chinese, with English abstr.).

Fang, S., G. Li, and X. Fu. 2004. Biomass production and bark yield in the plantations of Pteroceltis tatarinowii. Biomass Bioenergy 26:319-328.

Fu, L. 1991. China plant red data book. Sci. Press. Beijing (in Chinese).

Fu, X.X., S.Z. Fang, H.W. Wang, and C.Y. Hou. 2001. Studies on annual growth dynamics of one-year seedlings of Pteroceltis tatarinowii. J. of Nanjing For. Univ. 25:11-14 (Natural Sciences Edition).

Guo, S.J., H.Q. Ling, and F.L. Li. 2004. Physiological and biochemical basis of rooting of Pinus bungeana cuttings. J. Beijing For. Univ. 26:43-47 (in Chinese, with English abstr.).

Guo, X.F., X.L. Fu, D.K. Zang, and Y. Ma. 2009. Effect of auxin treatments, cuttings' collection date and initial characteristics on Paeonia 'Yang Fei Chu Yu' cutting propagation. Scientia Hort. 119:177-181.

Haile, G., K. Gebrehiwot, M. Lemenih, and F. Bongers. 2011. Time of collection and cutting sizes affect vegetative propagation of Boswellia papyrifera (Del.) Hochst through leafless branch cuttings. J. Arid Environ. 75:873-877.

He, S.G., T.Y. Yu, and L.F. Mai. 2002. Effects of IBA treatments on the root growth of hydroponic Aglaonema 'Silver Queen'. Acta Hort Sinica. 29:288-289 (in Chinese, with English abstr.).

Howard, B.H. 1996. Relations between shoot growth and rooting of cuttings in three contrasting species of ornamental shrub. J. Hort. Sci. Biotechnol. 71:591-605.

Husen, A. and M. Pal. 2007. Effect of branch position and auxin treatment on clonal propagation of Tectona grandis. New For. 34:223233.

Julia, A.C. and D.L. Jessica. 2013. Propagation of four underused native species from softwood cuttings. HortScience 48:1018-1020.

Klein, J.D., S. Cohen, and Y. Hebbe. 2000. Seasonal variation in rooting ability of myrtle (Myrtus communis L.) cuttings. Scientia Hort. 83:71-76

Li, X.H., H. Zhang, D.Y. Wang, L. Zhang, J.W. Shao, and X.P. Zhang. 2013. The genetic structure of endemic plant Pteroceltis tatarinowii by ISSR markers. Acta Ecol. Sin. 33:48924901 (in Chinese, with English abstr.).

Liu, C.C., Y.G. Liu, K. Guo, D.Y. Fan, G.Q. Li, Y.R. Zheng, L.F. Yu, and R. Yang. 2011. Effect of drought on pigments, osmotic adjustment and antioxidant enzymes in six woody plant species in karst habitats of southwestern China. Environ. Expt. Bot. 71:174-183.

Phillip, A.W., A.R. Timothy, J.D. Adam, P. Mark, M.V. Lisa, M. Ryan, and N.T. Robert. 2014 Propagation for the conservation of Pityopsis ruthii, an endangered species from the southeastern United States. HortScience 49:194200.

Severino, L.S., R.L.S. Lima, A.M.A. Lucena, M.A.O. Freire, L.R. Sampaio, R.P. Veras, K.A.A.L. Medeiros, V. Sofiatti, and N.H.C. Arriel. 2011. Propagation by stem cuttings and root system structure of Jatropha curcas. Biomass Bioenergy 35:3160-3166.

Sheng, M.D. 2006. Propagation technique by seeding of Pteroceltis tatarinowii. An Hui Agr. Sci. Bull. 12:152-177 (in Chinese).

Singh, B., R. Yadav, and B.P. Bhatt. 2012. Vegetative propagation of Dalbergia sissoo: Effect of growth regulators, length, position of shoot and type of cuttings on rooting potential in stem cuttings. For. Stud. China 14:187-192.

Tworkoski, T. and F. Takeda. 2007. Rooting response of shoot cuttings from three peach growth habits. Scientia Hort. 115:98-100.

Valerio, C., R. Youssef, and R. Eddo. 2010 Collection time, cutting age, IBA and putrescine effects on root formation in Corylus avellana L. cuttings. Scientia Hort. 124:189194.

Wei, X.L., L.F. Yu, S.Q. Zhu, and X.Z. Xu. 2007. Effect of soil drying-wetting alternation on physiology and growth of Pteroceltis tatarinowii seedlings. Scientia Silvae Sinicae. 43:2328 (in Chinese, with English abstr).

Yang, C.H. and X.P. Fang. 1996. Seeding propagation of Pteroceltis tatarinowii. Guizhou For. Sci. and Technol. 24:53-56 (in Chinese)

Zalesny, J.R.S., R.B. Hall, E.O. Bauer, and D.E. Riemenschneider. 2003. Shoot position affects root initiation and growth of dormant unrooted cuttings of Populus. Silvae Genet. 52(56):273-279.

Zhou, Q. 2000. Experimental guide of plant physiology. China Agr. Publ. House, Beijing. 115124, 111-112 (in Chinese). 